\title{
Fuentes de felicidad: ¿Qué hace feliz a la gente?
}

\author{
Reynaldo Alarcón ${ }^{1}$ \\ Universidad Ricardo Palma
}

\begin{abstract}
Se comunican los resultados de una investigación que tuvo los siguientes objetivos: (a) identificar los objetos preferidos para alcanzar la felicidad, y, (b) determinar si los objetos preferidos están asociados con el género, el estado conyugal y la edad. La muestra estuvo integrada por 163 personas: 81 hombres y 82 mujeres, de clase media de la ciudad de Lima. Se solicitó a los sujetos que seleccionaran, de una lista de 15 ítems, tres objetos que consideraban los más importantes para su felicidad. Los resultados señalan que los objetos preferidos fueron: "gozar de buena salud"; "estar bien con Dios" y "tener buena familia". No se encontraron diferencias significativas en la elección de los objetos según el género, aunque sí según la edad y el estado conyugal. El análisis de regresión múltiple indicó que los tres objetos considerados más importantes explican el $66 \%$ de la varianza de la variable felicidad. Se discuten los hallazgos y se hacen comparaciones con trabajos similares.

Palabras clave: felicidad, objetos de felicidad, género, estado conyugal, edad.
\end{abstract}

\section{Sources of happiness : What makes people happy?}

The present research had the following goals: (a) to identify the favorite objects to reach the happiness; and (b), to determine if the favorite objects are associated with the gender, the married condition and the age of the participant. The sample was integrated by 163 middle class people: 81 men and 82 women, all from Lima City. They were requested to choose, from a list of 15 items, the three objects that they consider the most important for happiness. The favorite objects were: "to have good health"; "to have a good relationship with God" and "to have a good family". There were not significant differences in the object choosing according to gender, although there were differences according to age and married condition. The analysis of multiple regression informed that the more important considered objects explain $66 \%$ of the variance of the variable happiness. The results are discussed and compared with similar works.

Key words: happiness, objects of happiness, gender, married state, age.

Psicólogo, Doctor en Filosofía y Psicología. Profesor Emérito de la Universidad Nacional Mayor de San Marcos y Doctor Honoris Causa de la Universidad Ricardo Palma. Es profesor Principal de la Facultad de Psicología de la Universidad Ricardo Palma y de la Escuela de Postgrado de la Universidad Femenina. Ha publicado numerosos trabajos de investigación empírica y artículos teóricos sobre temas psicológicos de su especialidad. Es miembro del Comité Editorial de la Revista Latinoamericana de Psicología (Bogotá), de la Junta de Consultores Editoriales de la Revista Interamericana de Psicología (San Juan, Puerto Rico) y miembro del Consejo Asesor de Cuadernos Argentinos de Historia de la Psicología. Correo electrónico: rcalarcon@terra.com.pe. 

¿Qué hace felices a los hombres y a las mujeres? Ésta es una pregunta central en la investigación de la felicidad. La pregunta se relaciona con la idea que dice que la felicidad implica la posesión de un bien o bienes deseados por una persona. Sin la posesión del bien u objeto valioso, la felicidad no tiene sentido, resulta un concepto vacío puesto que la obtención del objeto es lo que procura el bienestar subjetivo (SWB) que experimenta el individuo.

La tesis que sostiene que la felicidad conlleva la posesión del bien a que se aspira es de muy antigua data en la reflexión filosófica. Fue sostenida por el Eudemonismo, tendencia ética que enfatizó que la felicidad se alcanza al conseguirse el bien deseado; también sostuvo que no puede existir incompatibilidad entre felicidad y el objeto que la produce. En la misma línea de pensamiento, Aristóteles en su Ética a Nicómaco sostuvo que "lo placentero es alcanzar lo que deseamos"; más adelante equipara la felicidad con la autosuficiencia o autarquía (autarke), que la define como el estado en que nos hallamos faltos de nada, y la persona se basta a sí misma. El estagirita pregunta: "¿Por qué no afirmar que el hombre feliz es aquel que está suficientemente dotado de bienes externos, no durante algún periodo casual, sino durante toda su vida? Un día o un corto periodo de tiempo, no hace a un hombre dichoso y feliz" (Aristóteles, 1979, p.168177). Aristóteles sostuvo que para ser feliz uno debe disponer de bienes exteriores que permitan dedicarse a la vida contemplativa y satisfacer las propias necesidades. La autarquía a la que se refiere Aristóteles fue un concepto propuesto por Sócrates y elaborado por diversas escuelas helenísticas. Significaba la liberación de toda inquietud que conlleva disponer de bienes materiales; era la condición para hallar tranquilidad, paz espiritual y felicidad (Ferrater Mora, 1969). 
El supuesto de que la posesión del bien deseado genera felicidad, no significa reducirla al objeto que la produce; el objeto actúa sólo como generador de la experiencia subjetiva de bienestar, ésta es el efecto final de un proceso dinámico que se inicia con la elección del objeto considerado valioso, necesario e importante para una persona. A ello se suman los esfuerzos que a menudo realiza el individuo para lograrlo. Es pues el logro del objeto deseado lo que despierta el estado emocional de satisfacción; en tanto que el fracaso producirá sentimientos de desosiego, tristeza, frustración y conductas similares a la infelicidad.

En este análisis sucinto, el problema que lo genera es identificar los objetos o bienes que promueven la felicidad, a menudo denominados fuentes de felicidad. Al parecer, son de naturaleza variada; pueden ser, por ejemplo, éticos, económicos, religiosos, estéticos, sociales, biológicos, materiales e ideales. Se trata, ciertamente, de objetos materiales (v. gr: el dinero) o ideales (v. gr: la libertad), a los cuales las personas les asignan subjetivamente cualidades axiológicas. De aquí se infiere que un mismo objeto no siempre genera bienestar en todos los individuos; para unos puede detentar un alto valor, en tanto que para otros, el mismo objeto no lo tiene y hasta puede resultarle desagradable. Kant extrema la nota sosteniendo que todo hombre desea alcanzar la felicidad, pero que nunca puede decir de modo fijo lo que propiamente quiere y desea para ser verdaderamente feliz. ¿Quiere riqueza?, ¿quiere conocimiento y saber?, ¿quiere una vida larga?, ¿quiere tener salud? (Kant, 1946).

La diversidad de cosas que pueden hacer la felicidad individual, no descarta que existan ciertos objetos colectivamente deseados por una comunidad de individuos por efecto de influencias de la cultura que comparten. Es probable que los objetos materiales e ideales que determinan el estar subjetivamente bien no sean los mismos en todas las naciones. Lu y Shih (1997) han identificado en sujetos de 18 a 60 años de Taiwán, nueve fuentes de felicidad: gratificación de necesidades, armonía en las 
Fuentes de felicidad: ¿Qué hace feliz a la gente?

relaciones interpersonales, satisfacción de necesidades materiales, logro en el trabajo, sentir gusto con la vida, tener placer, autodominio y actualización personal, tener afectos positivos y poseer buena salud. Los autores señalan que la concepción china de felicidad tiene componentes únicos, como estar a gusto con la vida. Roiste (1996) reporta que en Irlanda las fuentes generadoras de felicidad eran la familia, los amigos y la vida social. La autora encontró diferencias según género, edad y estado marital. Lu, Gilmour y Kao (2001) examinaron las relaciones entre valores culturales y experiencias de felicidad en grupos de estudiantes universitarios de Taiwan y británicos. Encontraron una fuerte relación entre valores y felicidad en ambas muestras. Los valores de integración social y humanos tenían efectos sobre la felicidad.

Swinyard, Kau y Phua (2001) examinaron las relaciones entre felicidad, materialismo y experiencia religiosa, en muestras de adultos de Estados Unidos y Singapur. El término "materialismo", fue definido operacionalmente por la posesión de éxitos y adquisición de cosas como búsqueda de felicidad. Encontraron que la felicidad correlaciona negativamente con el materialismo en EEUU y en Singapur, aunque encontraron que los adultos de Singapur son menos felices y más materialistas que los de Estados Unidos. Los resultados apoyaron la hipótesis de que la felicidad tiene relación positiva con la religiosidad. Las personas felices no ven su religión como algo que ellos "hacen", sino como lo que ellos "son". Los autores concluyen que la felicidad no está asociada con la acumulación de bienes materiales. French y Joseph (1999) estudiaron si había asociación entre religiosidad y felicidad en 101 estudiantes universitarios. Encontraron que las puntuaciones altas en la Francis Scale of Acttitude towards Christianity, estaban asociadas con las puntuaciones altas en el Oxford Happiness Inventory. Asimismo hallaron una asociación positiva entre religiosidad y facetas del bienestar subjetivo. Francis, Jones y Wilcox (2000) examinaron tres grupos de sujetos, adolescentes, adultos jóvenes y adultos mayores, con el Oxford Happiness 
Inventory y la Francis Scale of Attitude toward Christianity. Los datos demostraron correlaciones positivas bajas entre felicidad y religiosidad en los tres grupos.

Diener y Oishi (2000) han examinado la literatura sobre la relación entre ingreso económico y bienestar subjetivo (SWB) en varios países. Destacan que la gente de las naciones adineradas son, en término medio, más felices que las personas de las naciones pobres; que la desigualdad del ingreso en las naciones produce inevitablemente efectos negativos; que la satisfacción de las necesidades aumenta la felicidad y que obtener el ingreso propuesto como meta produce satisfacción financiera. Myers (2000) observó que existe conexión entre riqueza y felicidad. Su afirmación la documenta con resultados hallados en Estado Unidos. A la pregunta: ¿qué mejoraría su calidad de vida?, la respuesta más frecuente fue: "más dinero". Personas que ganaban más de $\$ 75,000$ dólares informaron que les gustaría ser ricos. Myers observa que para el "sueño americano" la buena vida puede ser posible cuando se logra mayor riqueza. Anota, asimismo, que Inglehart ha encontrado en Estados Unidos, Canadá y Europa una correlación muy débil entre ingreso y felicidad personal; sin embargo, la felicidad tiende a bajar entre los muy pobres. En una investigación transnacional que comprendió 40 países, Schyns (1998) correlacionó felicidad con condiciones económicas y culturales. Ambos factores correlacionaron fuerte y positivamente con felicidad. Sin embargo, cuando exploró independientemente la influencia por separado de los dos predictores, encontró que sólo la prosperidad económica persistentemente correlacionó con felicidad; entre cultura y felicidad la correlación fue espuria. En el grupo de los países ricos halló una correlación positiva entre felicidad y cultura. Cummins (2000) ha revisado la literatura relativa al problema de ingreso personal y bienestar subjetivo, y sostiene que la creencia que el dinero tiene poca relevancia en la felicidad ha sido usada incorrectamente por la Teoría Homeostática del Bienestar Subjetivo. Ha encontrado que hay diferencias significativas entre niveles de bienestar subjetivo de gente 
Fuentes de felicidad: ¿Qué hace feliz a la gente?

rica, de medianos ingresos y gente pobre; de esto infiere que el dinero compra la felicidad en la magnitud en que los recursos externos permitan un funcionamiento óptimo del bienestar subjetivo del sistema homeostático. Lane (2000) ha llamado la atención de que no obstante que los ciudadanos de las avanzadas democracias mercantiles están satisfechos con su progreso material, muchos son presas del fantasma de la infelicidad. Hay evidencias -según ha sostenido- de creciente depresión, de una corrosión trágica de solidaridad familiar e integración de la comunidad. Observó que en EEUU ha declinado el número de gente que se considera feliz y que la filosofía utilitaria de la felicidad ha contribuido a la insatisfacción que la gente experimenta de la vida. Un alto ingreso contribuye casi nada a la felicidad, una vez que se está más allá del nivel de pobreza. El autor encuentra que en las economías avanzadas, las fuentes principales de felicidad son una buena familia y las amistades.

Se ha indagado por la relación entre felicidad y el sistema democrático de los países. Frey y Stutzer (2000) partieron de la hipótesis de que en una democracia desarrollada los ciudadanos son más felices. Sus análisis econométricos basados en 6000 personas de Suiza, han demostrado que el mayor desarrollo de las instituciones en las democracias influye en la felicidad de los individuos, que el alto ingreso económico está asociado con altos niveles de felicidad y que los desempleados son mucho menos felices que los empleados. Inglehart y Klingemann (2000) han examinado el bienestar subjetivo en 64 países. Entre sus hallazgos pueden mencionarse los que siguen: La felicidad es necesaria para una democracia estable; los sistemas políticos probablemente colapsen si mucha gente de un país está insatisfecha, pasado un periodo de tiempo. Los ciudadanos de democracias estables probablemente experimentan altos niveles de SWB y la inestabilidad política conduce a bajar los niveles promedios de bienestar subjetivo. Moller (2001) estudió los efectos de las elecciones democráticas de 1994 en Sudáfrica, sobre la satisfacción con la vida y la felicidad. Encontró, en 1999, que la división sembrada por 
el "apartheid" todavía se refleja en la felicidad. A pesar de algunas ganancias en las condiciones de vida, la felicidad y la satisfacción con la vida de los negros, subió solamente medio punto. Encontró entre los blancos, que perdieron legalmente su dominación política, mayor felicidad y satisfacción con la vida.

Las respuestas a la pregunta: ¿qué hace felices a los hombres y mujeres?, según Czikszentmihalyi (1999), han ido del extremo materialista de buscar la felicidad en las condiciones externas, al extremo espiritualista que considera a la felicidad como el resultado de una actitud mental. La investigación apoya ambas posiciones, el materialismo y el mentalismo, aunque el segundo produce resultados más fuertes, según el autor. En esta polarización hay lugar para otros matices; por ejemplo, un pragmatista podría sostener que lo que hace la felicidad es lo que conviene a sus intereses y es beneficioso para la vida; para un hedonista serán los objetos que producen placer, pero hay placeres sensibles y placeres espirituales, unos son más deseables que otros, y los hombres pueden elegir entre ellos. Czikszentmihalyi también señala que los psicólogos han redescubierto recientemente este tema, en el cual vienen trabajando. En el presente trabajo se aborda el problema de las fuentes externas de la felicidad y se tiene como propósito lo siguiente: (a) identificar los objetos preferidos para ser felices por un grupo de personas de clase media; y (b) establecer si los objetos o bienes preferidos están asociados con el género, el estado conyugal y la edad de los sujetos.

\section{Metodología}

\section{Participantes}

La muestra la conforman 163 personas, 81 varones y 82 mujeres, de clase media y media alta de la ciudad de Lima. Para analizar la presunta la influencia de la edad, se organizaron cinco grupos de 
Fuentes de felicidad: ¿Qué hace feliz a la gente?

edades de $20(\mathrm{n}=34), 30(\mathrm{n}=32), 40(\mathrm{n}=32), 50(\mathrm{n}=31)$ y $60(\mathrm{n}$ =34) años, cada grupo estuvo integrado por individuos que no pasaban la década, por ejemplo, el grupo de 20 años lo conformaron jóvenes de 20 a 29 años. La variable estado conyugal comprendió 56 solteros y 92 casados; viudos y divorciados fueron reunidos en el grupo "otros".

\section{Instrumentos}

Hemos utilizado una lista integrada por 15 objetos o bienes considerados valiosos para la felicidad. La lista fue elaborada en varias etapas. Inicialmente, se pidió a jóvenes universitarios y a personas adultas que escribieran libremente tres objetos o bienes que desearían tener para ser felices. Con las respuestas se formó una lista de 20 ítems. Esta lista fue administrada a un grupo distinto de personas, eliminándose de ella 5 ítems, sea porque no fueron elegidos o porque recibieron muy pocas elecciones. De esta manera, la prueba quedó integrada por 15 ítems que representan objetos valorados como importantes para lograr la felicidad.

La lista de 15 ítems lleva la siguic ntes instrucción: “¿Cuánto valora usted los siguientes objetos o cosas para ser feliz? Escoja solamente 3 objetos de los 15 de la lista. Empiece escribiendo número 1 delante del que considera más importante, el número 2 al segundo en importancia y el 3 a su tercera elección”.

\section{Procedimiento}

Las pruebas se administraron en forma colectiva al grupo de estudiantes universitarios; las personas de las demás edades absolvieron la prueba en forma individual en sus hogares. Colaboraron en la aplicación de las pruebas algunos estudiantes de los Talleres de Investigación Psicológica de la Universidad Ricardo Palma y estudiantes de la Maestría en Psicología de la Escuela de Postgrado de la Universidad Femenina. 


\section{Resultados}

\section{Objetos preferidos en primer lugar por la muestra total}

El Cuadro 1 presenta los porcentajes de respuestas que recibieron los objetos que ocuparon el primer lugar de preferencia de la muestra total. Obsérvese que la lista contiene sólo 13 objetos considerados subjetivamente importantes para ser feliz. De ellos, el mayor porcentaje lo obtiene "gozar de buena salud" (34\%), en segundo lugar "estar bien con Dios" $(22.8 \%)$ y en tercer término aparece "tener una buena familia" $(13.8 \%)$. Los más bajos porcentajes de elección corresponden a "tener un trabajo estable" $(0.6 \%)$ y "ser culto e informado" $(0.6 \%)$

\section{Cuadro 1}

Porcentajes de los objetos valorados en primer lugar

\begin{tabular}{|clr|}
\hline Rango & \multicolumn{1}{c|}{ Objeto } & $\%$ \\
\hline 1. & Gozar de buena salud & 34.0 \\
2. & Estar bien con Dios & 22.8 \\
3. & Tener una buena familia & 13.6 \\
4. & Vivir en paz interior & 9.3 \\
5. & Alcanzar éxito & 8.0 \\
6. & Tener libertad & 3.1 \\
7. & Tener dinero & 2.5 \\
8. & Ser honesto & 1.9 \\
9. & El amor romántico & 1.2 \\
10. & Tener amigos & 1.2 \\
11. & Hacer el bien a los demás & 1.2 \\
12. & Tener un trabajo estable & 0.6 \\
13. & Ser culto e informado & 0.6 \\
\hline
\end{tabular}

Nota. $N=162$

Los tres objetos convertidos en bienes deseados son de naturaleza distinta. El primero, "salud", es un bien de orden biológico, presupone el buen estado de los órganos y el funcionamiento normal del 
Fuentes de felicidad: ¿Qué hace feliz a la gente?

organismo como totalidad psicofísica. El segundo bien, "Dios", ente supremo que expresa la religiosidad manifiesta del grupo examinado. En tercer término se encuentra "tener una buena familia", que alude a un grupo de individuos de nexos consanguíneos, con una historia de antiguas interacciones entre sus miembros, unida por factores afectivos y que posee una identidad propia, lo cual pone la diferencia entre las diversas familias. La sétima ubicación del ítem "tener dinero", refleja un mediano interés por esta fuente de felicidad. De otro lado, llama la atención la baja importancia de la muestra examinada por "tener un trabajo estable", en un tiempo marcado por una alta tasa de desempleo, al punto de constituir un objetivo político de los candidatos en las últimas elecciones presidenciales y un reclamo popular vigente. Junto con "ser culto y bien informado" ocupan el último lugar entre los objetos deseados.

En el Cuadro 2 se ha acumulado el número de elecciones que recibieron los 15 objetos preferidos en primero, segundo y tercer lugar. Se advierte una ligera modificación en el orden obtenido en el Cuadro 1 elaborado solamente con el primer lugar de preferencia. En efecto, "gozar de buena salud" siempre mantiene el primer lugar de preferencia con 110 respuestas $(67.5 \%)$ de un total de 163 sujetos. El segundo lugar lo ocupa "tener una buena familia", con $54.6 \%$ de elecciones; en tanto que el tercer puesto corresponde a "estar bien con Dios", que obtiene $41 \%$. Este Cuadro revela la escasa selección que han obtenido los ítems "destruir obstáculos", que hace referencia a una conducta agresiva utilizada para conseguir alguna meta, eliminando los obstáculos que se interpongan. El último lugar lo ocupa "tener poder", exaltado por Nietzche como voluntad de poderío. En rigor, el poder no es ni bueno ni malo, es una conducta instrumental que puede utilizarse para realizar acciones valiosas o para efectuar acciones éticamente repudiables, como oprimir al prójimo o satisfacer necesidades egoístas. Por otro lado, han recibido muy poco apoyo tres valores supuestamente importantes, como son: "libertad", "honestidad" y "amistad"; ocupan el $10^{\circ}, 11^{\circ}$ y $13^{\circ}$ lugar respectivamente. Estos índices de valoración podrían explicarse por fenómenos 
conyunturales que experimenta la sociedad peruana actual, como es la crisis de valores de la que con frecuencia se habla.

\section{Cuadro 2}

Porcentajes de frecuencias acumuladas del primero, segundo y tercer lugar de los 15 objetos

\begin{tabular}{|llrr|}
\hline Rango & \multicolumn{1}{c}{ Objeto } & $f$ & $\%$ \\
\hline 1. & Gozar de buena salud & 110 & 67.5 \\
2. & Tener una buena familia & 89 & 54.6 \\
3. & Estar bien con Dios & 67 & 41.1 \\
4. & Vivir en paz interior & 49 & 30.1 \\
5. & Tener dinero & 30 & 18.4 \\
6. & Alcanzar éxito & 29 & 17.8 \\
7. & Hacer el bien a los demás & 23 & 14.1 \\
8. & Tener un trabajo estable & 20 & 12.3 \\
9. & Ser culto e informado & 19 & 11.7 \\
10. & Tener libertad & 17 & 10.4 \\
11. & Ser honesto & 13 & 8.0 \\
12. & El amor romántico & 9 & 5.5 \\
13. & Tener amigos & 6 & 3.7 \\
14. & Destruir los obstáculos & 4 & 2.5 \\
15. & Tener poder & 2 & 1.2 \\
\hline
\end{tabular}

Nota. $N=163$.

Objetos preferidos y su asociación con el género, estado conyugal y edad

Los tres objetos preferidos con mayores frecuencias del Cuadro 1 no mantienen el mismo orden de rango según las variables género, estado conyugal y edades. Los Cuadros 3,4 y 5 contienen los porcentajes de respuestas que recibió cada objeto valorado de acuerdo a las variables mencionadas.

El género, "gozar de buena salud" ocupa el primer lugar de preferencia con un porcentaje ligeramente mayor en varones que en mujeres. En cuanto a "estar bien con Dios", ocupa el segundo lugar. Se 
Fuentes de felicidad: ¿Qué hace feliz a la gente?

puede advertir que la preferencia por Dios es más elevada en el grupo femenino (27.2\%) que en el masculino (18.5\%); sin embargo, al verificarse la magnitud de la diferencia entre ambos porcentajes se halló $z=1.33$, valor no significativo a $p>.05$. El tercer lugar lo ocupa "tener una buena familia". En contra de lo que podría esperarse, un número mayor de varones (16\%) manifiesta preferencias más acentuadas por la familia, que el grupo de mujeres (11\%), aunque la diferencia no es significativa. En suma, según el género: salud, Dios y familia ocupan las tres primeras preferencias.

\section{Cuadro 3}

Porcentajes de preferencias de cada objeto valorado en primer lugar, según género

\begin{tabular}{|lrrr|}
\hline Objeto & Hombre & Mujer & $\%$ medio \\
\hline dinero & 2.7 & 1.2 & 2.5 \\
salud & 35.8 & 32.1 & 34.0 \\
amor & 1.2 & 1.2 & 1.2 \\
honestidad & 2.5 & 1.2 & 1.9 \\
éxito & 7.4 & 8.6 & 8.0 \\
libertad & 6.2 & 0.0 & 3.1 \\
Dios & 18.5 & 27.2 & 22.8 \\
paz & 6.2 & 12.3 & 9.3 \\
amigos & 1.2 & 1.2 & 1.2 \\
familia & 16.0 & 11.1 & 13.6 \\
trabajo & 1.0 & 0.0 & 0.6 \\
bien & 0.0 & 1.0 & 1.2 \\
culto & 0.0 & 1.2 & 0.6 \\
\hline
\end{tabular}

Nota. En cursiva los objetos que ocupan las tres primeras preferencias.

Los resultados por estado conyugal se muestran en el Cuadro 4. Se observa en la columna media total que salud, Dios y familia ocupan en ese orden los tres primeros lugares. Sin embargo, cuando se analiza la tabla por las categorías de la variable, aparecen algunas diferencias importantes. En el grupo de solteros el ítem "alcanzar éxito" $(20 \%)$ obtiene elecciones muy cercanas a salud (21.8\%) y Dios (21.8\%), desplazando a familia, con solo $7.3 \%$ de preferencias, y aún menor que el ítem "vivir en paz interior" (10.9\%). La variable "éxito" 
obtiene bajísimos porcentajes en los grupos de casados y otros (viudos y divorciados). Asimismo, la poca importancia que tiene "familia" para los solteros, contrasta con los mayores porcentajes que corresponden a las otras dos categorías de la variable estado conyugal. Si bien salud (21.8\%) ocupa el primer término en el grupo "solteros", el porcentaje de elecciones que ha recibido es menor que para los "casados" (41.3\%). Al comparar ambos porcentajes, el valor de $z=$ 2.46 es significativo a $p<.05$. La diferencia observada entre los porcentajes de solteros y "otros" (33.3\%) carece de significación estadística. En el grupo "otros" (viudos y divorciados), "familia" y "vivir en paz interior" obtienen el mismo porcentaje (13.3\%), y ambos ítems ocupan el tercer lugar.

\section{Cuadro 4}

Porcentajes de preferencias de cada objeto valorado, según estado conyugal

\begin{tabular}{|lrrrr|}
\hline Objetos & Solteros & Casados & Otros & $\%$ medio \\
\hline dinero & 5.5 & 1.1 & .5 & 2.5 \\
salud & 21.8 & 41.3 & 33.3 & 34.0 \\
amor & 1.8 & 1.1 & .0 & 1.2 \\
honestidad & .0 & 3.3 & .0 & 1.9 \\
éxito & 20.0 & 1.1 & 6.7 & 8.0 \\
libertad & 5.5 & 2.2 & .0 & 3.1 \\
Dios & 21.8 & 22.8 & 26.7 & 22.8 \\
paz interior & 10.9 & 7.6 & 13.3 & 9.3 \\
amigos & 1.8 & .0 & 6.7 & 1.2 \\
familia & 7.3 & 17.4 & 13.3 & 13.6 \\
trabajo & .0 & 1.1 & .0 & 0.6 \\
hacer el bien & 3.6 & .0 & .0 & 1.2 \\
ser culto & .0 & 1.1 & .0 & .6 \\
\hline
\end{tabular}

Nota. En cursiva los objetos que ocupan las tres primeras preferencias.

Con respecto a la variable grupos de edad, en el grupo de 20 años, el ítem "éxito" (23.5\%) se encuentra en primer término; en segundo lugar se ubica salud (20.6\%), en tanto que Dios y familia alcanzan cada cual $14.7 \%$. Parece lógica la preferencia del grupo de 20 
Fuentes de felicidad: ¿Qué hace feliz a la gente?

años de seleccionar "alcanzar éxito" como el primer bien deseado; al parecer, lograr las metas propuestas que conllevan al éxito se encuentra entre los objetivos principales de la juventud. Este ítem obtiene muy bajos porcentajes en las demás edades. El ítem "salud" obtiene porcentajes elevados en todas las demás edades, pero en 40 años registra el valor más alto $(45.2 \%)$. Al comparar este porcentaje con el que corresponde a 20 años $(20.6 \%$ ), encontramos que $z=2.15$ es significativo a $p<.05$. También se advierte que los porcentajes que corresponden a Dios varían. En 20 años es $14.7 \%$ en tanto que en 50 años registra el más alto valor (37.7\%). La diferencia entre ambos porcentajes, $z=2.22$, es significativa a $p<.05$. En el Cuadro 5 se observa también que a los 60 años "familia" y "paz interior" tiene iguales porcentajes de elección (11.8\%). Más allá de las diferencias entre los grupos de edad, según esta variable los objetos preferidos son salud, Dios y familia.

\section{Cuadro 5}

Porcentajes obtenidos por los objetos valorados en primer lugar, según edades

\begin{tabular}{|lrrrrrr|}
\hline Objeto & 20 años & 30 años & 40 años & 50 años & 60 años & Media \% \\
\hline dinero & 8.8 & .0 & 3.2 & .0 & .0 & 2.5 \\
salud & 20.6 & 31.3 & 45.2 & 38.7 & 35.3 & 34.0 \\
amor & 2.9 & .0 & 3.2 & .0 & .0 & 1.2 \\
honesto & .0 & 3.1 & .0 & .0 & 5.9 & 1.9 \\
éxito & 23.5 & 3.1 & 9.7 & .0 & 2.9 & 8.0 \\
1. & 5.9 & 3.1 & 0.0 & 3.2 & 2.9 & 3.1 \\
Dios & 14.7 & 21.9 & 16.1 & 39.7 & 23.5 & 22.8 \\
paz & 8.8 & 12.5 & 6.5 & 6.5 & 11.8 & 9.3 \\
amigos & .0 & 3.1 & .0 & .0 & 2.9 & 1.2 \\
familia & 14.7 & 18.8 & 9.7 & 12.9 & 11.8 & 13.6 \\
trabajo & .0 & .0 & 3.2 & .0 & .0 & .6 \\
bien & .0 & 3.1 & .0 & .0 & 2.9 & 1.2 \\
culto & .0 & .0 & 3.2 & .0 & .0 & .6 \\
\hline
\end{tabular}

Nota. En cursiva los objetos que ocupan los tres primeros lugares, por edad.

Con la finalidad de determinar si las variables género, estado conyugal y edad están asociadas con la preferencia de objetos hemos 
determinado los valores de Chi cuadrado $\left(X^{2}\right)$ y la Razón de Verosimilitud $(R V)$. Los resultados se aprecian en el Cuadro 6. El valor de $X^{2}=14.29$ entre género y objetos preferidos carece de significación estadística a $p<.05$. Esto indica que el género no ejerce influencia en la elección de los objetos considerados valiosos para ser feliz, es decir, hombres y mujeres prefieren los mismos objetos con las diferencias porcentuales no significativas que hemos señalado.

Al analizar la relación entre estado conyugal y objetos preferidos se halló $X^{2}=40.35$, valor significativo a $p<.05$. Vale decir que solteros, casados y el grupo "otros" prefieren objetos diferentes. Finalmente, el valor de $X^{2}=57.49$, que es altamente significativo a $p<$ .01 , señala que los objetos preferidos por los grupos de edad no son siempre los mismos o que hay diferencias en cuanto a la intensidad de las elecciones. En suma: dentro de los límites de este trabajo podría afirmarse que el estado conyugal y la edad son dos variables que influyen en las personas para elegir los objetos que las hacen felices.

\section{Cuadro 6}

Asociación entre los objetos valorados y las variables género, estado conyugal y edad

\begin{tabular}{|llll|}
\hline Variables & $X^{2}$ & $g l$ & $R V$ \\
\hline Género & 14.292 & 12 & 17.866 \\
Estado conyugal & $40.351^{*}$ & 24 & 43.242 \\
Edades & $57.489^{* *}$ & 48 & 58.6 \\
\hline
\end{tabular}

Nota. $* p<.05 \quad * * p<.01$

Análisis de correspondencias entre los cinco primeros "objetos preferidos" y las variables estado conyugal y grupos de edad

Vamos a analizar la estructura de la asociación entre las variables estado civil y edad con los cinco primeros objetos preferidos: salud, Dios, familia, éxito y paz interior. A la vez, se representará gráficamente la correspondencia entre las categorías de las variables 
Fuentes de felicidad: ¿Qué hace feliz a la gente?

mencionadas con la variable "objetos preferidos". Los datos se han tratado mediante Análisis de Correspondencias Simple (ANACOR). Este análisis se basa en la transformación del valor de $X^{2}$ en una medida métrica de distancia (Hair, Anderson, Tatham y Black, 1999).

El Cuadro 7 recoge el resultado obtenido del análisis de la tabla de contingencia de las variables estado conyugal y los cinco primeros objetos seleccionados. El Cuadro indica una solución de dos dimensiones, aunque de importancia desigual; los valores singulares se interpretan como las correlaciones entre las puntuaciones de las filas y las columnas de la tabla de contingencia y son similares a los coeficientes de correlación de Pearson. El cuadrado de un valor singular es la inercia de cada dimensión y significa una medida de la importancia de cada dimensión. Según lo dicho, se observa que la inercia de la primera dimensión (.175) es mucho más elevada que la correspondiente a la segunda dimensión (.006). La primera dimensión explica el $96.6 \%$ de la inercia total, en tanto que la segunda explica sólo el 3.4\%. En otros términos, la primera dimensión explica casi la totalidad de la información de la tabla de contingencia, no incluida en el presente informe.

\section{Cuadro 7}

Valores singulares, inercia y proporciones de la inercia total, explicada y acumulada, por dimensión de estado conyugal y objetos preferidos

\begin{tabular}{|c|c|c|c|c|}
\hline \multirow{2}{*}{ Dimensión } & \multirow{2}{*}{ Valor singular } & \multirow{2}{*}{ Inercia } & \multicolumn{2}{|c|}{ Proporción de la inercia } \\
\hline & & & Explicada & Acumulada \\
\hline 1 & 419 & .175 & 966 & .966 \\
\hline 2 & .079 & .006 & 034 & 1. 000 \\
\hline Total & & .181 & 1.000 & 1.000 \\
\hline
\end{tabular}

El mapa perceptual, Figura 1, se ha construido con los datos del Cuadro 8 que contiene las puntuaciones de filas y columnas originales para las dimensiones 1 y 2 de las variables estado conyugal y objetos preferidos. En el mapa, las categorías de estado conyugal se localizan 
más próximas a los objetos con los cuales están asociadas y más le jos de los objetos con los que tienen asociaciones débiles.

En primer término, se observa que las tres categorías de la varia ble estado civil: casados, solteros y otros (viudos y divorciados) $\mathrm{s}$ encuentran muy distantes entre ellos. El grupo "casados" se halla cel cano a salud, familia y Dios; "soltero" se acerca a salud, Dios y éxi to; en tanto que la categoría "otros" está más cercana a "paz inte rior". Examinando el monto con que contribuye cada objeto preferid a la inercia en cada dimensión, se comprueba que el $79.5 \%$ del tot de la inercia de la primera dimensión es explicada por "éxito", sien do el más distante entre los objetos preferidos. En la segunda dimen sión "paz interior" explica el 53.5\% de la inercia total. No hemo consignado las contribuciones a la inercia total de cada categoría d las dos variables a cada dimensión porque abultaría demasiado est reporte.

\section{Cuadro 8}

Puntajes por filas y columnas para estado conyugal (filas) y objetos preferidos (columnas)

\begin{tabular}{|lrc|}
\hline Estado & \multicolumn{2}{c|}{ Dimensiones } \\
Conyugal & 1 & 2 \\
\hline soltero & .944 & -.017 \\
casado & -.455 & -.127 \\
otros & -.361 & .868 \\
\hline Objetos & & \\
Preferidos & 1 & 2 \\
\hline salud & -.338 & -.157 \\
Dios & .021 & .207 \\
familia & -.459 & -.207 \\
paz & .280 & .630 \\
éxito & 1.977 & -.329 \\
\hline
\end{tabular}

Nota. Es normalización simétrica. 
Fuentes de felicidad: ¿Qué hace feliz a la gente?

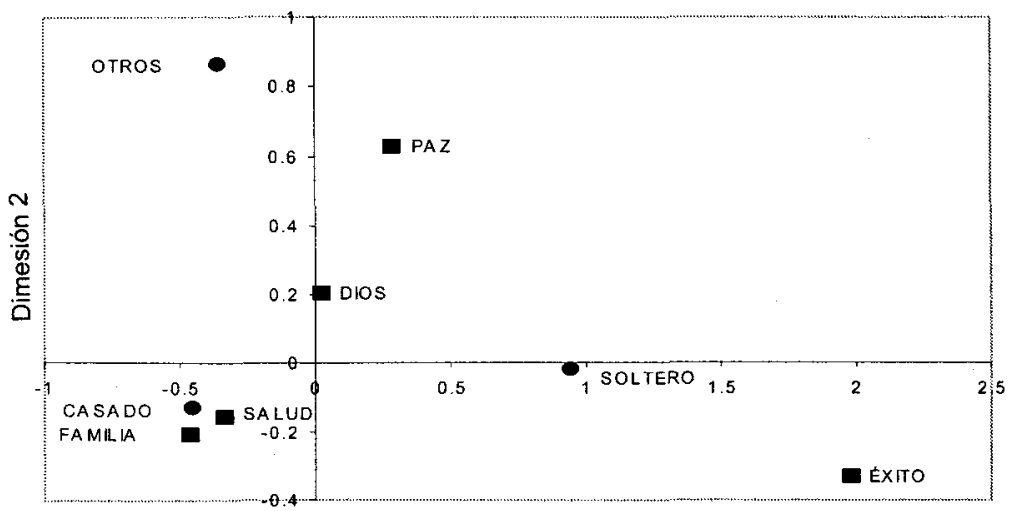

Dimesión 1

Figura 1. Mapa perceptual de los cinco primeros objetos preferidos, según estado conyugal.

En el Cuadro 9 se presentan los autovalores, la inercia de cada dimensión y los porcentajes de la inercia explicada y acumulada para las cuatro dimensiones. La primera y la segunda dimensión explican el $90.8 \%$ de la inercia total, una solución de tres dimensiones aporta sólo el $.084 \%$. Por tanto, la solución bidimensional es adecuada para los análisis posteriores, que es la solución que proporciona el programa SPSS para interpretar las relaciones entre todas las categorías de las variables.

\section{Cuadro 9}

Valores singulares, inercia y proporciones de la inercia explicada y acumulada por dimensión de objeto preferido y edad

\begin{tabular}{|rcccc|}
\hline \multirow{2}{*}{ Dimensión } & Valor singular & Inercia & \multicolumn{2}{c|}{ Proporciones de la varianza } \\
& & & Explicada & Acumulada \\
\hline 1 & .397 & .158 & .791 & .791 \\
2 & .152 & .023 & .116 & .908 \\
3 & .129 & .017 & .084 & .991 \\
4 & .041 & .002 & .009 & 1.000 \\
Total & & .200 & 1.000 & 1.000 \\
\hline
\end{tabular}


Las puntuaciones originales de las dimensiones 1 y 2 , de filas y columnas, correspondientes a grupos de edad y objetos preferidos del Cuadro 10, se han graficado en la Figura 2. La lectura de ella por cuadrantes muestra que los grupos 50 y 60 años se hallan muy cercanos a Dios, 30 años a "paz interior", en tanto que "salud" y "familia" guardan distancias aproximadas con todas las edades. Destaca, asimismo, la asociación única entre 20 años y "éxito". En suma: la mayor o menor proximidad entre las categorías en el plano bidimensional significa un mayor o menor grado de asociación entre ellas.

Cuadro 10

Puntajes por filas y columnas para las variables edad (filas) y objetos preferidos (columnas)

\begin{tabular}{|lrr|}
\hline $\begin{array}{l}\text { Edades } \\
\text { (años) }\end{array}$ & 1 & Dimensiones \\
\hline 20 & -1.170 & .189 \\
30 & .207 & .444 \\
40 & -.127 & .740 \\
50 & .569 & .003 \\
60 & .476 & .077 \\
\hline Objetos & & \\
preferidos & 1 & 2 \\
\hline salud & .212 & -.434 \\
Dios & .381 & .179 \\
familia & -.093 & .510 \\
paz & .018 & .516 \\
éxito & -2.000 & -.144 \\
\hline
\end{tabular}

Nota. Es normalización simétrica. 
Fuentes de felicidad: ¿Qué hace feliz a la gente?

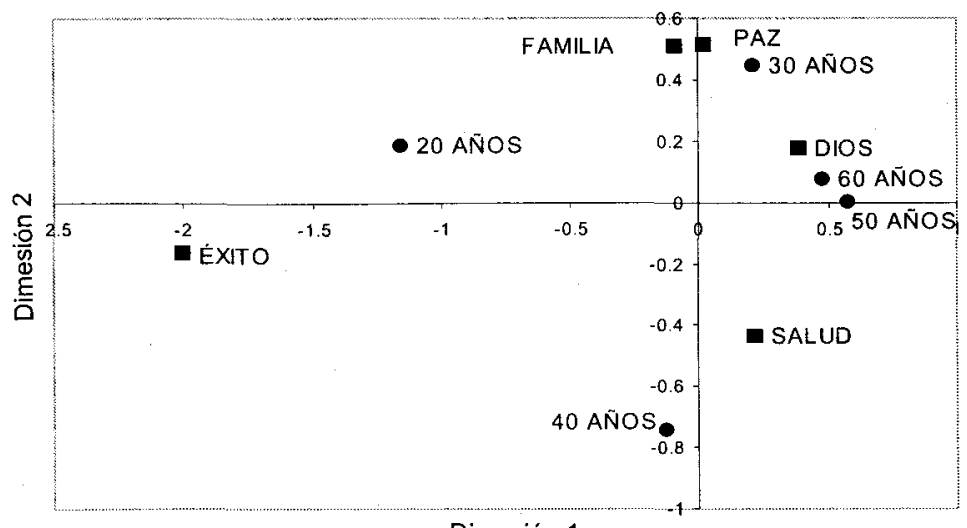

Dimesión 1

Figura 2. Mapa perceptual de los cinco primeros objetos preferidos, según edades.

\section{Proporción de la variable felicidad explicada por los tres objetos preferidos: salud, Dios y familia}

Con la finalidad de determinar la relación entre felicidad (estar subjetivamente bien) y los tres objetos valorados más importantes, hemos sometido a análisis de regresión múltiple las puntuaciones obtenidas en la "Escala de Satisfacción con la Vida" de E. Diener (Alarcón, 2000) y las puntuaciones alcanzadas por los tres primeros objetos preferidos por la muestra. En la ecuación de regresión, felicidad actúa como variable dependiente, y actúan como variables predictoras, "gozar de buena salud", "estar bien con Dios" y "tener buena familia".

El análisis de varianza de la regresión fue de $F=3.73$, significativo a $p<.05$, indica que el coeficiente de correlación múltiple, $R$ $=.257$, expresa una relación significativa entre las tres variables predictoras y la variable dependiente. El coeficiente de determinación múltiple, $R^{2}=0.66$, indica que las variables predictoras en conjunto explican el 66 por ciento de la varianza de la variable felicidad y, asimismo, el poder explicativo de la ecuación de regresión. El $R^{2}$ ajustado $=.048$, más cauteloso, reduce la proporción de la varianza expli- 
cada. En cualquier caso, se trata de una magnitud importante. El resto de la varianza de la variable criterio, se distribuiría entre los demás objetos y quizá entre otros no considerados. Para terminar, podría afirmarse que los tres bienes preferidos, salud, Dios y familia, son altamente importantes para el bienestar subjetivo del grupo examinado.

\section{Cuadro 11}

Análisis de regresión múltiple de satisfacción con la vida ${ }^{\text {, }}$ salud Dios $^{b}$, familia $^{b}$.

\begin{tabular}{|ll|}
\hline Coeficiente $R$ & .257 \\
Coeficiente $R^{2}$ & .066 \\
$R^{2}$ ajustado & .048 \\
Error Std. Estimación & 3.27 \\
ANOVA de regresión, $F$. & $3.733(p<.05)$ \\
\hline
\end{tabular}

Nota. ${ }^{\mathrm{a}}$ variable dependiente ${ }^{\mathrm{b}}$ variable predictiva.

\section{Discusión}

Hemos encontrado que los objetos más altamente apreciados por la gente para lograr la felicidad fueron, en este orden, los siguientes: "gozar de buena salud", "estar bien con Dios" y "tener una buena familia". La lectura inmediata de los tres bienes elegidos hace ver que los tres son de naturaleza variada, no corresponden a bienes materiales y ninguno de ellos apunta hacia fines hedonistas o utilitarios.

La buena salud, que obtiene el porcentaje más alto, es de orden biológico, inherente a la persona y, en cierta manera, su cuidado depende de ella. En rigor, la salud es producto de la interacción del individuo con factores económicos, sociales y culturales; esta interacción se expresa en niveles de salud física y mental. Buena parte de la felicidad, entendida como bienestar personal, está condicionada por una eficiente salud, y viceversa; entendemos que es por esto que gran 
parte de la muestra la selecciona como primer objeto deseable. En otros términos: sin salud no hay felicidad.

"Estar bien con Dios" refleja la arraigada fe religiosa, extendidamente católica, a la que tradicionalmente se adhieren los hombres y mujeres del país, y que el grupo examinado reafirma. Estar bien con Dios significa para los fieles creer en la creación del hombre por Dios, en el pecado original, en la resurrección de los muertos, en la Inmaculada Concepción, en el juicio final y en otros mandatos de la teología católica. Los creyentes recurren a la suprema bondad divina para superar sus sufrimientos, para solicitar el perdón de sus pecados, para conseguir alguna cosa deseada y en momentos difíciles, como catástrofes naturales, para detener la furia de la naturaleza. No nos compete discutir la congruencia de estas creencias con la realidad científica, ni las formas del comportamiento religioso de los fieles, solamente señalamos que sus acciones están orientadas por la profunda fe que profesan y que ella los lleva a elegir a Dios para alcanzar la felicidad.

La preferencia por "tener una buena familia", trasunta su identificación con el grupo originario de pertenencia. Pero no se trata de lazos formales como los establecidos en alguna forma de organización artificial, se trata de una red afectiva de sentimientos de cariño, de apoyo, protección y hasta defensivos ante eventualidades externas negativas que pueden afrontar los miembros de la familia. Quizá la expresión afectiva de mayor calidez es el amor materno y la reciprocidad de los hijos, sobre todo hacia la madre. Este estilo de vida es muy generalizado sobre todo en la familia tradicional peruana. Cuando se habla de "tener una buena familia" nos parece que se alude a estas características de integración socio-afectiva del grupo de individuos consanguíneos. Obviamente, también hay grupos familiares con lazos de integración muy débiles.

De los tres objetos considerados altamente valiosos para alcanzar la felicidad, algunos de ellos han sido señalados también como fuentes 
de felicidad en algunos países. Por ejemplo, Lu y Shi (1997) en Taiwan, identificaron nueve fuentes de felicidad, entre ellas "poseer buena salud" . Roiste (1996) reportó que en Irlanda "la familia" era considerada importante para ser feliz. Aunque no hemos encontrado informes explícitos que sindiquen a Dios como fuente de felicidad, hay investigaciones colaterales al tema. French y Joseph (1999) han encontrado una correlación positiva entre puntuaciones logradas en una escala de felicidad y otra de actitudes religiosas. Sin embargo, Frances, Jones y Wilcox (2000) observan que la correlación entre ambas variables es baja y positiva.

Nuestros resultados guardan correspondencia con La Encuesta del Milenio, conducida por Gallup International y otros institutos asociados similares, sobre una muestra representativa a nivel mundial de 50,000 personas. Se preguntó: “¿Qué es lo que más importa en la vida? Las dos primeras respuestas en el mundo fueron: "tener buena salud" (44\%) y "tener una vida familiar feliz" (38\%). Algunas variaciones en el orden se advierten por países (Telefónica, El Comercio y Datum, 2000a). Aunque la pregunta no alude directamente a la felicidad, sino a la vida, que es un concepto más amplio que incluye la felicidad, los resultados aportan información valiosa para compararlos con los hallados por nosotros en Lima. La Encuesta del Milenio preguntó también por "lo que menos importa en la vida" y la respuesta con mayor porcentaje fue: "Ser creyente de mi religión" (38\%). Sin embargo, en una encuesta que específicamente tuvo por tema la religión, al preguntar: "¿Qué tan importante es Dios en su vida?", el $46 \%$ en el mundo respondió "muy importante"; este porcentaje subió notoriamente al $75 \%$ en el continente americano. En el Perú, el $74 \%$ de la muestra respondió: "muy importante". Ante la pregunta: ¿Qué religión practica?, el $81 \%$ respondió: la religión católica (Telefónica, El Comercio y Datum, 2000b). En suma: estos datos confirman la importancia que la religión tiene en la vida y en la felicidad de las personas. 
Llama la atención que el ítem "tener dinero" ocupe el séptimo lugar, apenas con $2.5 \%$ de preferencias. Puede entenderse que para la muestra examinada el dinero no es un factor esencialmente prioritario para ser feliz, quizás porque se trate de gente de clase media y media alta. Este hallazgo discrepa con los encontrados en sujetos de economías fuertes de Europa y Estados Unidos. Al respecto, varios investigadores (Cummins, 2000; Myers, 2000; Schyns, 1998) informan que existe conexión entre bienestar subjetivo y riqueza, ingreso personal o condiciones económicas. Diener y Oishi (2000) sostienen que la gente de los países adinerados son, en término medio, más felices que la gente de las naciones pobres. Por otro lado, Inglehart (Myers, 2000) arguye que la correlación entre ambas variables es muy débil, aunque la felicidad es baja entre los muy pobres. Todo esto lleva a considerar que los sujetos con ingresos económicos muy bajos, al punto que no les permiten cubrir sus necesidades básicas, son personas muy poco felices y aquellos que se encuentran en pobreza extrema están muy lejos de serlo. Observaciones practicadas en gente en estado de pobreza crítica, confirman la presencia de tristeza, sufrimiento, abandono, sentimientos de apatía y desmoralización (Alarcón, 1986).

Los tres objetos preferidos por la muestra total mantienen el mismo orden de rango según el género de los sujetos. Salud, Dios y familia son igualmente preferidos por varones y mujeres, aunque las mujeres registran un porcentaje relativamente más alto $(27.2 \%)$ que los hombres (18.5\%). Estos datos son congruentes con la extendida idea que atribuye mayor religiosidad a las mujeres que a los hombres. Sin embargo, la diferencia no es estadísticamente significativa.

Con relación al estado conyugal, en términos generales, los tres objetos preferidos mantienen el mismo orden de rango: salud, Dios y familia. Este orden se altera en el grupo de solteros: salud y Dios mantienen sus mismos lugares, en tanto que "familia" es desplazado al quinto puesto, siendo sustituido por "tener éxito". Nos parece que 
la razón más consistente que pueda explicar este hecho es que el grupo de solteros está integrado en su mayoría por estudiantes universitarios. Parece lógico suponer que su mayor interés sea obtener éxito profesional. En efecto, esta observación es confirmada por el grupo de 20 años, donde "obtener éxito" ocupa el primer lugar de preferencia; salud, Dios y familia comparten el tercer lugar. El análisis de los datos por estado conyugal y grupos de edad, lleva a inferir que estas variables influyen en la selección de objetos considerados subjetivamente importantes para ser feliz.

Para terminar, el análisis de regresión múltiple indicó que los tres objetos que gozan de mayor preferencia: salud, Dios y familia, convertidos en variables predictoras, explican el 66\% de la varianza de la variable felicidad, que es un valor importante. En conclusión: salud, Dios y familia son bienes considerados altamente valiosos para lograr la felicidad en la muestra examinada.

\section{Referencias}

Alarcón, R. (1986). Psicología, pobreza y subdesarrollo. Lima: Educativa.

Alarcón, R. (2000). Variables psicológicas asociadas con la felicidad. Persona, 3,147-157.

Aristóteles (1979). Etica a Nicómaco. En: Obras Filosóficas (pp. 155-234). México: Educativa

Cummins, R. A. (2000). Personal income and subjective well-being. A Review Journal of Happiness Studies, 1, 133-158.

Csikszentmihalyi, M. (1999). If we are so rich, why aren't we happy? American Psychologist, 54, 821-827.

Diener, E. y Oishi, S. (2000). Money and happiness: Income and subjective well-being across nations. En: E. Diener \& E. Such (Eds.), Culture and subjective well-being (pp. 185-218). Cambridge, MA: The MIT Press. 
Fuentes de felicidad: ¿Qué hace feliz a la gente?

Ferreter Mora, J. (1969). Diccionario de Filosofía (tomo I). Buenos Aires: Editorial Sudamericana.

Francis, L. J., Jones, S. H. y Wilcox, C. (2000). Religiosity and happiness: During adolescence, young, adulthood, and later life. Journal of Psychology and Christianity, 19, 245-257.

French, S. y Joseph, S. (1999). Religiosity and its association with happiness, purpose in life, and self- actualization. Mental Health, Religion and Culture, 2, 117-120.

Frey, B. S. y Stutzer, A. (2000). Happiness prosper in democracy. Joumal of Happiness Studies, 1, 79-102.

Hair, J. F., Anderson, R. E., Tatham, R. L. y Black, W. C. (1999). Analisis Multivariante. Madrid: Prentice Hall.

Inglehart, R. y Klingemann, H. S. (2000). Genes, culture, democracy and happiness. En: E. Diener y E. Suh (Eds.), Culture and subjetive well-being (pp.165-183). Cambridge, MA: The MIT Press.

Kant, M. (1946). Fundamentación de la metafísica de las costumbres. Buenos Aires: Espasa Calpe.

Lane, R. E. (2000). The loss of happiness in market democracies. New Haven: Yale University Press.

Lu, L. y Shih, J. B. (1997). Sources of ha spiness: A qualitative approach. Journal of Social Psychology, 13, 181-188.

Lu, L., Gilmour, R. y Kao, S. F. (2001). Cultural values and happiness: An East- West dialogue. Journal of Social Psychology, 141, 477493.

Moller, V. (2001). Happiness trends under democracy : Where will the new South African set level come to rest? Journal of Happiness Studies, 2, 33-53.

Myers, D. G. (2000). The funds, friends, and faith of happy people. American Psychologist, 55, 56-67.

Roiste, A. (1996). Sources of worry and happiness in Ireland. Irish Journal of Psychology, 17, 193-212.

Schyns, P. (1998). Crossnational differences in happiness: Economic and cultural factors explored. Social Indicators Research, 43, 326. 
Swinyard, W.R., Kau, A. K. y Phua, H. Y. (2001). Happiness, materialism, and religious experience in the US and Singapore. Journal of Happiness Studies, 2, 13-32.

Telefónica, El Comercio y Datum. (2000a). La Encuesta del Milenio. Lo que más importa en la vida. Lima: El Comercio.

Telefónica, El Comercio y Datum. (2000b). La Encuesta del Milenio. Religión. Lima: El Comercio. 